\title{
Evaluation of the Gauss-Eyring model to predict thermal inactivation of micro-organisms at short holding times
}

\author{
R.A.H. Timmermans ${ }^{\mathrm{a}, *}$, H.C. Mastwijk ${ }^{\mathrm{a}}$, M.N. Nierop Groot ${ }^{\mathrm{a}}$, M.A.J.S. Van Boekel ${ }^{\mathrm{b}}$ \\ ${ }^{\text {a } W a g e n i n g e n ~ F o o d ~ \& ~ B i o b a s e d ~ R e s e a r c h, ~ W a g e n i n g e n ~ U n i v e r s i t y ~ \& ~ R e s e a r c h, ~ P . O . ~ B o x ~ 17, ~} 6700$ AA Wageningen, The Netherlands \\ ${ }^{\mathrm{b}}$ Food Quality \& Design Group, Wageningen University \& Research, P.O. Box 8129, 6700 EV Wageningen, The Netherlands
}

\section{A R T I C L E I N F O}

\section{Keywords:}

Thermal inactivation

Gauss-Eyring model

Isothermal kinetics

Isotime kinetics

Predictive microbiology

\begin{abstract}
A B S T R A C T
Application of mild (non)-thermal processing technologies have received considerable interest as alternative to thermal pasteurisation, because of its shorter holding time and lower temperature aiming for an improved product quality. To understand and develop these alternative technologies, like pulsed electric fields, a proper comparison between the conventional thermal and alternative process is necessary. Up to recent, no suitable models were available to predict the inactivation of micro-organisms by a thermal process at a chosen short holding time, due to non-linearity. The recently developed Gauss-Eyring model with two variables temperature and time has the properties to be a suitable model to apply for short holding times, and was tested for this purpose.

Therefore, this study aims to validate if the Gauss-Eyring model can be used to describe non-linear isothermal (a fixed temperature with varying holding time) and isotime (a fixed holding time with varying temperature) thermal inactivation data, and if it is a suitable model to predict the thermal inactivation as a function of temperature for short holding times.

Inactivation data of Escherichia coli, Listeria monocytogenes, Lactobacillus plantarum, Salmonella Senftenberg and Saccharomyces cerevisiae in orange juice were collected via isothermal and isotime inactivation kinetics. Survival of the tested micro-organisms was modelled with the Gauss-Eyring model, which contains three parameters $\sigma$, $\operatorname{Tr}$ and $Z$. The transition of 'no inactivation' to 'inactivation' (i.e. the 'shoulder' in inactivation curves) can be characterised as the temperature-time $(T, t)$ combination where $T=\operatorname{Tr}-Z \cdot \log _{10}(t)$, with $\operatorname{Tr}$ as the reference temperature defined for $1 \mathrm{~s}$ treatment, $Z$ as the temperature needed for a 10 -fold increase of decrease of the holding time $t$, and $\sigma$ as the temperature width of the distribution.

The Gauss-Eyring model fitted well to the experimental data, and revealed different sensitivity for the tested micro-organisms. Based on the parameter estimations, survival curves for the desired short holding times were predicted.
\end{abstract}

\section{Introduction}

Thermal pasteurisation of food products is widely used to eliminate a desired number of micro-organisms and to inactivate enzymes. In order to achieve a sufficient level of inactivation, the process has to be carried out at sufficient high temperatures and for a sufficient amount of time. Although inactivation of micro-organisms and enzymes increases with temperature and duration of the heating process, the use of high temperatures for a longer time, will also (partly) destroy compounds responsible for fresh flavour and nutrients in the product. Therefore, alternative milder preservation processes have received considerable interest over the last decades, as they allow processing at lower temperatures and/or shorter holding times compared to conventional thermal processes, aiming for an improved, yet safe, product quality. Alternative methods can be either optimised thermal processes, such as ohmic heating and microwave heating, or nonthermal processes, such as pulsed electric fields (PEF) and high hydrostatic pressure. These non-thermal techniques can both be used as single technology, or in a combination with mild heat, to optimise for microbial inactivation and quality retention. In an industrial setting, PEF processing is usually combined with mild heat to enhance inactivation, while impact on product attributes is limited (Raso et al., 2014; Timmermans et al., 2014).

To better understand the electroporation and/or thermal effect on the microbial inactivation in a combined process of PEF and mild heat, a comparison to a conventional thermal process is important. However,

\footnotetext{
* Corresponding author.

E-mail address: rian.timmermans@wur.nl (R.A.H. Timmermans).
} 
comparison of the two processes is difficult, or not feasible, as different set-ups and time scales are used to measure microbial inactivation kinetics. The most common method to measure thermal inactivation of a microbial population is based on isothermal kinetics. This method of isothermal kinetics is based on fast heating of a microbial sample to a desired temperature, followed by sampling at regular (holding) times, to enumerate to the number of survivors.

Contrary, in emerging technologies like continuous PEF processes, the microbial inactivation kinetics cannot be characterised by a holding time series, as the temperature holding section is absent. The PEF treated product is immediately cooled after leaving the treatment zone where electric pulses are received, at the same point where the highest temperature is reached. By the design of a continuous flow PEF process, kinetic inactivation series can be made by variations of electric field strength, duration of the pulse and/or number of pulses applied to the product, resulting in different maximum temperatures (Raso et al., 2014). As the residence time in the treatment chambers is fixed and no holding time is used, inactivation kinetics of a PEF treatment can be characterised as series with different maximum temperatures and a fixed 'holding' time. Often the intensity of the PEF treatment is expressed in electrical energy applied to the system, but this can be converted to maximum temperatures using the specific heat capacity of the matrix (Siemer et al., 2014; Timmermans et al., 2014).

For a proper comparison between the conventional thermal process and a PEF treatment combined with mild heat, temperature-time conditions should be equal for both processes. Since the temperature-time exposure in a PEF process involves a short time $(\sim 1 \mathrm{~s})$ to leave the treatment chamber and enter the cooling section, an accurate estimation of the thermal inactivation at this temperature-time combination is essential.

It is therefore important to define a method and model to describe 'isotime' inactivation: a single holding time with varying temperatures. As a preparatory step we need to consider a two variable (temperature and time) thermodynamic model for inactivation to compare data that is obtained either as constant temperature or at fixed holding time.

Thermal inactivation kinetics is often described by first-order kinetic models, with parameters $D_{T}$ and $Z$. $D_{T}$, the decimal reduction time, is defined as the time needed to reduce the number of viable microorganisms in suspension with a factor 10 , at temperature $T$. The $Z$-value is defined as the change in temperature required to change $D_{T}$ by a factor of 10 . The parameter $D_{T}$ has been widely used in the calculation of the efficacy of pasteurisation and sterilisation processes, conceivably because it is so simple (Peleg and Normand, 2004; Van Boekel, 2008). Although there are micro-organisms that show linear or approximately linear semi-logarithmic survival curves, most microbial survival curves are not linear in practice (Van Boekel, 2002).

In order to account for the usually observed non-linearity, (empirical) models have been proposed to describe curves with a shoulder, curves with a tail (or biphasic curves) or curves including both a shoulder and a tail (sigmoid curves). Examples of these models include the Weibull model (Peleg and Cole, 1998; Van Boekel, 2002), biphasic linear model (Cerf, 1977), biphasic logistic model (Whiting, 1993), lognormal distribution (Aragao et al., 2007), reparameterized Gompertz model (Den Besten et al., 2006) and Geeraerd model (Geeraerd et al., 2000). Although these non-linear models fit very well to the survival data, most of these kinetic models are kinetic models with time as a single variable, and not both temperature and time as variables. The temperature dependence of the $D_{T}$-value is analysed using secondary models (Arrhenius-like) to obtain a $Z$-value. Secondary models based on polynomials accounting for additional variables $(T, \mathrm{pH}$, water activity) have been studied (Gil et al., 2016), but it is questionable if and how these models can be used to describe isotime inactivation, which requires extrapolation to very short holding times.

Recently, a thermodynamic model (Gauss-Eyring) for enzyme inactivation was presented, with model parameters reference temperature $\operatorname{Tr}$ and $Z$-value that are directly linked to standard activation enthalpy and entropy values of proteins (Mastwijk et al., 2017). This model was also explored as global model for the microbial inactivation of Listeria monocytogenes exposed to combined heat and $\mathrm{pH}$ stress. Interestingly, this primary model expresses the inactivation kinetics as a function of both temperature and time. The characteristics of this model allow to handle data sets where inactivation is observed as a single holding time with temperature as a variable, i.e. to handle datasets where treatment time cannot be varied, and to make predictions for processes with very short holding times.

The objective of this study was to validate the Gauss-Eyring model to describe non-linear isothermal as well as 'isotime' thermal inactivation data of Escherichia coli, Listeria monocytogenes, Lactobacillus plantarum, Salmonella Senftenberg and Saccharomyces cerevisiae, and to predict the thermal inactivation of these five micro-organisms as a function of temperature at short, fixed holding times.

\section{Material and methods}

\subsection{Micro-organisms and culture conditions}

Fresh cultures of Escherichia coli ATCC 35218 were prepared by plating from frozen stock culture on TSB (Oxoid) agar plates. Plates were incubated overnight $(\mathrm{o} / \mathrm{n})$ at $37^{\circ} \mathrm{C}$. A single colony isolate was used to inoculate a $100 \mathrm{~mL}$ flask with $10 \mathrm{~mL}$ TSB broth and cultivated for $24 \mathrm{~h}$ at $20^{\circ} \mathrm{C}$ in an Innova shaking incubator $(180 \mathrm{rpm})(2 \mathrm{nd} \mathrm{o} / \mathrm{n})$. From this culture, $200 \mu \mathrm{L}$ was used to inoculate $19.8 \mathrm{~mL}$ fresh TSB broth supplemented with $1 \%$ glucose (Sigma-Aldrich) ( $100 \mathrm{~mL}$ flask) and incubated for $24 \mathrm{~h}$ at $20^{\circ} \mathrm{C}$ and $180 \mathrm{rpm}(3 \mathrm{rd} \mathrm{o} / \mathrm{n})$. The cultivation of Salmonella Senftenberg ATCC 43845 was similar to the protocol above, for the other micro-organisms specific agar composition and different incubation temperatures for the first $\mathrm{o} / \mathrm{n}$ cultivation were used: Listeria monocytogenes NV8 was incubated at $30{ }^{\circ} \mathrm{C}$ using BHI agar (Oxoid), Lactobacillus plantarum ATCC 14917 was incubated at $30{ }^{\circ} \mathrm{C}$ using MRS broth (Merck) and Saccharomyces cerevisiae CBS 1544 was incubated at $25{ }^{\circ} \mathrm{C}$ using glucose-peptone-yeast agar, containing $40 \mathrm{~g}$ glucose, $5 \mathrm{~g}$ peptone (Fluka) and $5 \mathrm{~g}$ yeast extract (Oxoid) per $1 \mathrm{~L}$ distilled water. $1 \%$ glucose was added to the medium during the third $\mathrm{o} / \mathrm{n}$ cultivation to mimic sugar content in fruit juice, resulting in a reduction of the $\mathrm{pH}$ for E. coli, S. Senftenberg and L. monocytogenes, when compared to the $\mathrm{pH}$ of the medium without extra glucose (Table 1). After the $3 \mathrm{rd} \mathrm{o} / \mathrm{n}$ incubation, microbial cells were pelleted by centrifugation (4000 rpm, $5 \mathrm{~min}$ ) at $20^{\circ} \mathrm{C}$. Pellet was resuspended in $20 \mathrm{~mL}$ sterile peptone physiological salt diluent (PSDF, Tritium) and centrifuged again at same conditions. This step was repeated once, and after the third centrifugation step, pellet was dissolved in $20 \mathrm{~mL}$ pasteurised (30 min kept at $98^{\circ} \mathrm{C}$ ) orange juice (Minute Maid, original) to a cell density of $10^{7}-10^{8} \mathrm{cfu} / \mathrm{mL}$ (yeast) or $10^{8}-10^{9} \mathrm{cfu} / \mathrm{mL}$ (bacteria).

\subsection{Heat treatment}

For the thermal treatment, $130 \mu \mathrm{L}$ of the inoculated orange juice was transferred into a $200 \mu \mathrm{L}$ glass capillary (1.6 mm diameter, $125 \mathrm{~mm}$ length, Blaubrand ${ }^{\circledast}$ Intramark, Wertheim, Germany). Both ends were

Table 1

Effect of $1 \%$ glucose addition on the $\mathrm{pH}$ of the medium during the third overnight incubation. $t=0$ is the $\mathrm{pH}$ measured at the start of the overnight cultivation, when the glucose is added. $t=24 \mathrm{~h}$ is at the end of the third overnight cultivation.

\begin{tabular}{llll}
\hline Species/strains used & $\begin{array}{l}\mathrm{pH} \text { at } \\
t=0 \mathrm{~h}\end{array}$ & $\begin{array}{l}\mathrm{pH} \text { at } t=24 \mathrm{~h} \\
\text { without 1\% glucose }\end{array}$ & $\begin{array}{l}\mathrm{pH} \text { at } t=24 \mathrm{~h} \\
\text { with 1\% glucose }\end{array}$ \\
\hline Escherichia coli & 7.1 & 8.1 & 5.1 \\
Lactobacillus plantarum & 5.5 & 4.5 & 4.5 \\
Listeria monocytogenes & 7.3 & 5.9 & 5.1 \\
Saccharomyces cerevisiae & 5.0 & 4.5 & 4.5 \\
Salmonella Senftenberg & 7.1 & 8.2 & 5.1 \\
\hline
\end{tabular}




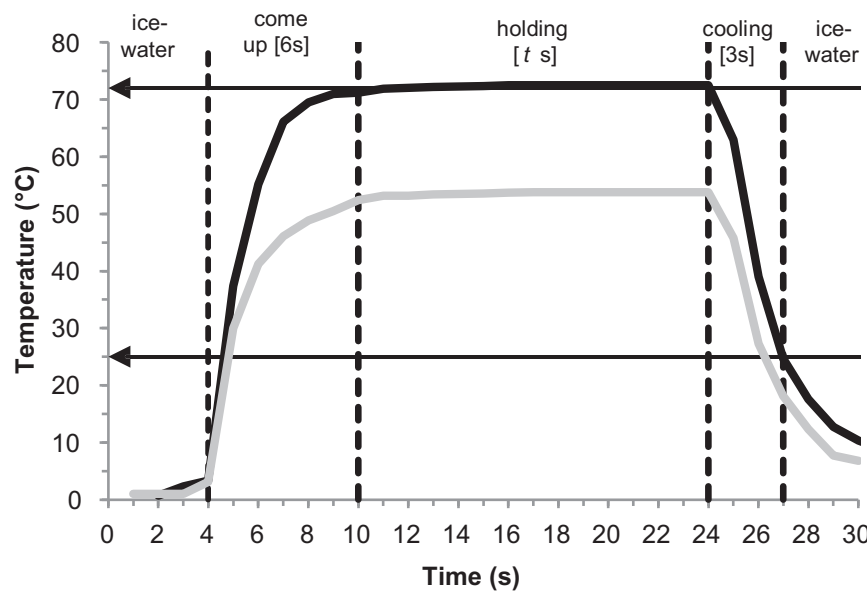

Fig. 1. Example of heating profile of a microbial suspension in orange juice in a capillary heated for $14 \mathrm{~s}$ at $54{ }^{\circ} \mathrm{C}$ (grey line) and $72{ }^{\circ} \mathrm{C}$ (black line).

sealed in a gas flame, leaving a sufficient air column to avoid heating of the microbial suspension during sealing. Capillaries were heat treated in a circulating water bath. Before and immediately after the heat treatment samples were stored in ice-water.

Temperature was measured in a capillary with open end, filled with $130 \mu \mathrm{L}$ suspension, by using a mini-hypodermic thermocouple (HYP-OT-type, Omega) to determine come-up time, holding time and cooling time. The total treatment can be characterised by a come-up time of $6 \mathrm{~s}$ (which is the time needed from $0{ }^{\circ} \mathrm{C}$ to $>95 \%$ of the desired temperature), a holding time (chosen for the specific treatment) and a cooling time of $3 \mathrm{~s}$ (from desired temperature to temperatures $<25^{\circ} \mathrm{C}$ ) (Fig. 1). Only the 'holding times' at the desired temperature were used for calculations, come-up time and cooling time were not used. The reason why this is sufficient will be explained in the next section, after introduction of the Gauss-Eyring model. Isothermal survival curves were taken with chosen, fixed temperatures $\left[52-65^{\circ} \mathrm{C}\right]$ and varying holding times [14-3004 s], and isotime survival curves were taken for selected, fixed holding times [4-184 s] and varying temperatures $\left[46-73^{\circ} \mathrm{C}\right]$.

Capillaries were aseptically opened and serially diluted in sterile PSDF and plated on suitable agar plates (medium supplemented with $15 \mathrm{~g}$ agar/L (Oxoid) and $0.1 \%$ sodium pyruvate (Sigma Aldrich)) to enhance outgrowth of sub-lethally damaged cells (McDonald et al., 1983; Sharma et al., 2005). Surviving cells were enumerated after 4-5 days at $25{ }^{\circ} \mathrm{C}\left(S\right.$. cerevisiae), $30{ }^{\circ} \mathrm{C}$ (L. monocytogenes and L. plantarum) and $37^{\circ} \mathrm{C}$ (E. coli and $S$. Senftenberg).

The total number of temperature-time conditions was too large to test all combinations of each strain on a single day. Therefore, experiments were executed over multiple days starting with cultivation of the same microbial stock culture, kept in $15 \%(\mathrm{v} / \mathrm{v})$ glycerol and stored at $-80^{\circ} \mathrm{C}$. This stock was thawed and frozen before the start of each cultivation, and biological variability for the different cultivations of the same culture could be evaluated as well.

\subsection{Inactivation model}

To describe the thermal inactivation of the vegetative micro-organisms as a function of temperature and time, the Gauss-Eyring model was used (Mastwijk et al., 2017). This Gauss-Eyring model is based on the Cumulative Distribution Function (CDF) for the standard normal distribution (Gauss) with $\mu$ for mean and $\sigma$ for standard deviation. The function $(F)$ of the CDF is given in Eq. (1), with erf as the error function, being the integral of the Gaussian probability distribution.

$F(x)=\Phi\left(\frac{x-\mu}{\sigma}\right)=\frac{1}{2}\left[1+\operatorname{erf}\left(\frac{x-\mu}{\sigma \sqrt{2}}\right)\right]$
For inactivation studies, where the degree of inactivation is often plotted as $\log _{10}\left(N / N_{0}\right)$, it is appropriate to use the complementary function of the CDF, Erfc, given in Eq. (2).

$\operatorname{erfc}(x)=1-\operatorname{erf}(x)$

Although the Weibull CDF could be used as an alternative model, this would miss some of the important features of using the erfc (Aragao et al., 2007).

To describe the degree of inactivation, $\log _{10}\left(N / N_{0}\right)$, as a function of temperature and time, parameters $\mu$ and $x$ in Eq. (1) were replaced by $T c(t)$ and $T$, respectively, in Eq. (3a), where $N(t, T)$ is the number of surviving micro-organisms after exposure to a temperature $T$ for a holding time $t(\mathrm{~s}), N_{0}$ is the initial number of micro-organisms at $t=0 \mathrm{~s}, T$ is the temperature of the treatment $\left({ }^{\circ} \mathrm{C}\right), T c(t)$ is the critical temperature, describing the transition of 'no inactivation' to 'the start of inactivation' $\left({ }^{\circ} \mathrm{C}\right.$ ) (shoulder) at a specific time $t$, and $\sigma$ the temperature width (the uncertainty in the transition temperature) of the survival function $\left({ }^{\circ} \mathrm{C}\right)$, a characteristic of the population under study.

$\log _{10}\left(\frac{N(t T)}{N_{0}}\right)=\log _{10}\left(\frac{1}{2}\left[\operatorname{erfc}\left(\frac{T-T c(t)}{\sigma \sqrt{2}}\right)\right]\right)$

The critical temperature, $T c(t)$, is a function of the holding time $t$ (s) and $Z\left({ }^{\circ} \mathrm{C}\right)$, which is the temperature needed to reduce or increase the holding time by a factor of 10 to reach the same level of inactivation, $\tau=1 \mathrm{~s}$ a chosen unit of time and $\operatorname{Tr}$ is the reference temperature in ${ }^{\circ} \mathrm{C}$ defined for a treatment of $1 \mathrm{~s}$, given in Eq. (3b). Note that the model parameter reference time $\tau$ is fixed by the particular choice of the unit of time (s or min) used for inactivation studies and the corresponding reference temperature $\operatorname{Tr}$ is defined by the outcome of the inactivation experiment (Mastwijk et al., 2017).

$\operatorname{Tc}(t)=\operatorname{Tr}-Z \cdot \log _{10}(t / \tau)$

The variables in the model are temperature and time $(T, t)$ and the model parameters are the reference temperature, $Z$-value and temperature width $(\operatorname{Tr}, Z, \sigma)$. The relation between these three model parameters is visualised in Fig. 2(A, B). In Fig. 2A, the Gauss-Eyring model is presented for three different values of $\sigma$, with same critical temperature $T c(t)$ at the same $\operatorname{Tr}, Z$ and chosen, fixed time $t . T c(t)$ represents a characteristic temperature at which $50 \%$ of the population is inactivated, corresponding to $\log _{10}\left(N / N_{0}\right)=-0.30$, regardless of the value of parameter $\sigma$. A smaller value of $\sigma$ induces a faster inactivation (steeper inactivation curve), meaning more inactivation $\log _{10}\left(N / N_{0}\right)$ at temperature $T>T c(t)$. The relation between parameter $Z$ and $T c(t)$, given in Eq. (3b), is illustrated in Fig. 2B. Increasing or decreasing the holding time $t$ will change the value of $T c(t)$, resulting in a temperature shift (shoulder) for the start of the inactivation curve. The $Z$-value indicates the temperature shift of this $T c(t)$, when the holding time is changed by a factor 10 . This definition is identical to the definition of the $Z$-value in first-order kinetics, where $Z$ is the temperature change required for a ten-fold change in the $D_{T}$-value, visualised in Fig. 2D. This $D_{T}$-value is the time required to inactivate the number of microorganism by a factor 10 at a given temperature $\mathrm{T}\left(D_{T}\right.$-value, visualised in Fig. 2C).

The Gauss-Eyring model presented is a static model i.e. the temperature-time combination is defined for a stationary treatment temperature. In an experimental setting using a capillary technique a sample cannot be instantaneously heated to reach a stationary temperature. This suggests that in principle, a dynamical model should be used to account for the coming up and cooling times. However, in the case of the Gauss-Eyring model the static approach for the reported experimental temperature-time combinations is an accurate approximation. The reason is that the mathematical line shape for the inactivation rate of the Gauss-Eyring model, $\mathrm{d} S / \mathrm{d} t$, is a sharp peaked function around $\operatorname{Tr}-T(t)-Z \cdot \log _{10}(t)=0$. This means that the integral with respect to time to obtain $S(T(t), t)$ ) only contributes 

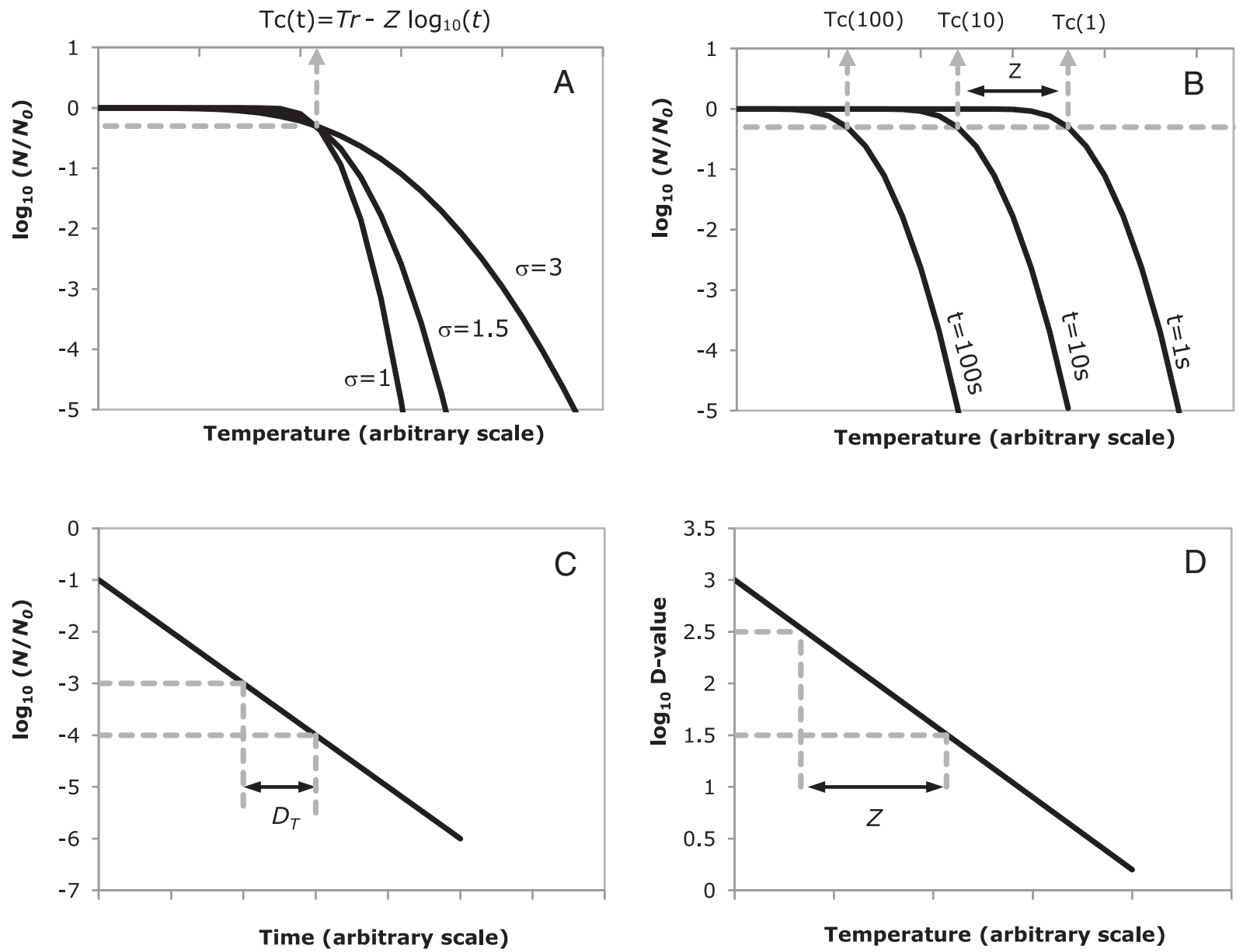

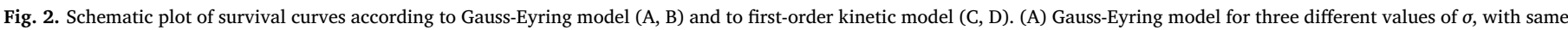

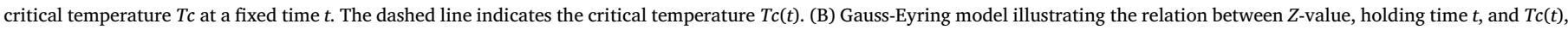
using one $\sigma$. (C) First order kinetics showing the $D_{T}$-value concept. (D) First order kinetics illustrating the $Z$-value concept.

significantly for temperature-time combinations $T(t)=T r-Z \cdot \log _{10}(t)$ within the temperature interval of $[T-\sigma, T+\sigma]$. This is a property of sharp peaked distributions (Dirac delta function) (Reiff, 1965). The definition of the stationary temperature according to Fig. 1 is where the stationary temperature is defined by the $95 \%$ level of the come-up time. The static model therefore provides an excellent approximation for the dynamical situation, even for come-up times that are relatively long with respect to the (short) holding time.

\subsection{Mathematical modeling and statistical analysis}

The Gauss-Eyring model was fitted to the data by means of nonlinear least squares, using the software package Athena Visual Studio version 14.2 (2016) (http://www.athenavisual.com).

Outcome and statistics of non-linear least squares fit routines were validated against Maximum Likelihood Estimates (MLE) fitting estimated with software package R ( R Core Team, 2016) with domain optimization for parameter estimates using generalized simulated annealing (Xiang et al., 2013). Although the definition of the error function $\operatorname{erf}(x)$ was different among the software programs, it was found that fit results of both methods were identical, both for quantitative and qualitative purposes.

The model given in Eqs. (3a) and (3b) was fitted to the inactivation data collected for each individual overnight culture, taken from the same frozen stock culture. For data series where only the temperature was varied at a single fixed time, no $Z$ value can be determined. In this case the model was reduced to a model with parameters $\operatorname{Tr}$ and $\sigma$ (Eq. (3a)). The reference temperature $\operatorname{Tr}$ is given for the fixed time used.
When the exposure times were varied for an individual cultivation, Eq. (3a) and $3 \mathrm{~b}$ were fitted to complete $(T, t)$ data sets, and an additional $Z$ value was obtained. In this case, the reference temperature $\operatorname{Tr}$ is defined for $t=1 \mathrm{~s}$. In this way 2 or 3 model parameters were obtained for each individual cultivation.

Alternatively, Eqs. (3a) and (3b) was fitted to the inactivation data of all overnight cultures, i.e. one fit to the data sets of all cultivations at once. With this method, only three parameters $\operatorname{Tr}, Z$ and $\sigma$ were determined as an average of all cultivations.

The goodness-of-fit was determined by evaluation of the distribution of the residuals and Sum of Squared Residuals (SSr). Comparison of the approach to fit the model to each individual cultivation or the single fit to all the cultivations at once, was done by comparison of the Bayesian Information Criterion (BIC) values. In Eq. (4) the definition for BIC is given, wherein $p$ is the number of fitted parameters and $n$ is the number of data points.

$B I C=n \cdot \ln \left(\frac{S S_{r}}{n}\right)+p \cdot \ln (n)$

The first term in Eq. (4) indicates that a better fit of the model to the data is obtained for smaller BIC values, whereas the second term is a penalty for the introduction of too many parameters. One BIC value could be determined for the individual fits for each cultivation. Herefore, the sum of all $S S r$ values for the individual cultivations was taken, $p$ was the total number of model parameters, being $2(\sigma, T r)$ or $3(\sigma, T r$, $Z$ ) for each cultivation and $n$ the total number of data points. For the other approach, a fit to the data of all cultivations at once, a single value for $S S r$ was determined. In this case the number of model parameters is 


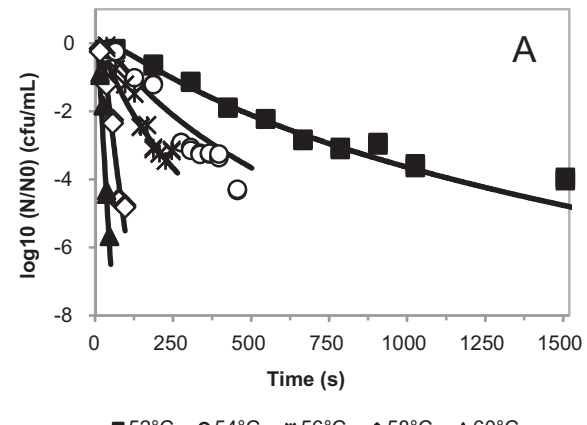

$=52^{\circ} \mathrm{C} \quad 054^{\circ} \mathrm{C} \times 56^{\circ} \mathrm{C} \quad \diamond 58^{\circ} \mathrm{C} \quad \triangle 60^{\circ} \mathrm{C}$
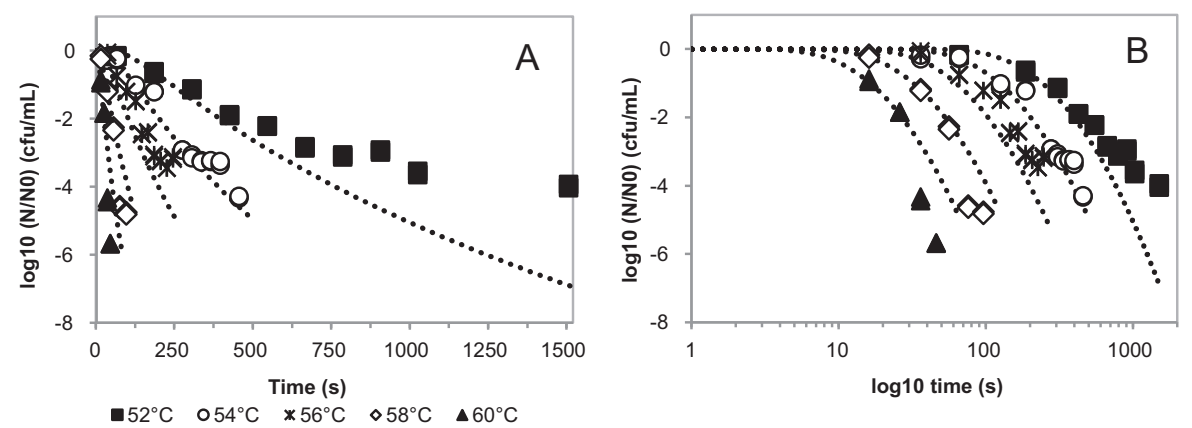

- $52^{\circ} \mathrm{C} \quad 054^{\circ} \mathrm{C} \quad * 56^{\circ} \mathrm{C} \quad \diamond 58^{\circ} \mathrm{C} \quad \triangle 60^{\circ} \mathrm{C}$
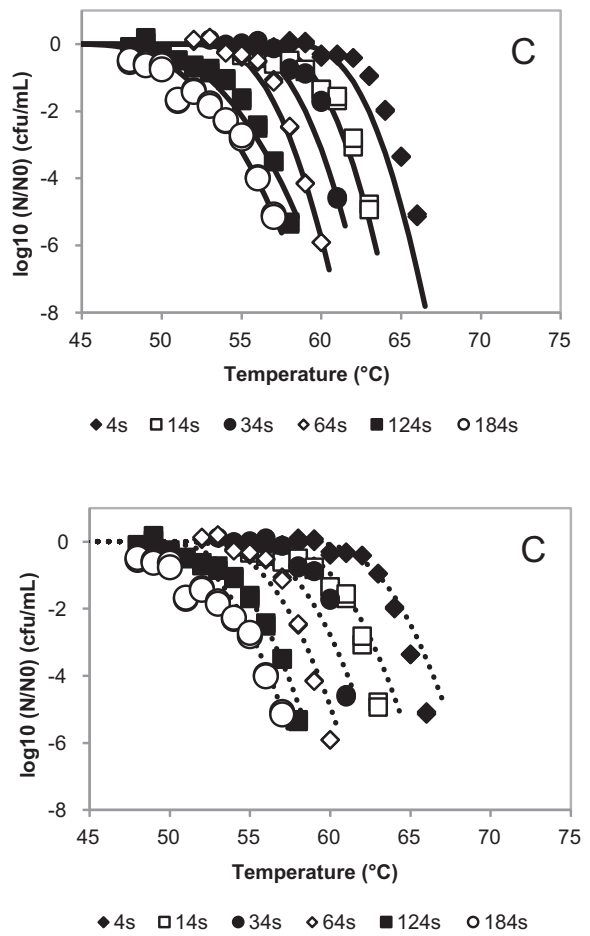

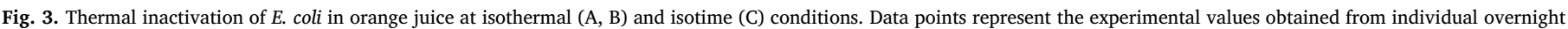
cultures from the same frozen stock.

Upper panel: continuous lines present the fit of the Gauss-Eyring model fitted to each individual culture.

Lower panel: dotted lines present the fit of the Gauss-Eyring model as single model with parameter estimations based on the average of cultivation.

$p=3$, and $n$ has the same value as the for sum of the individual fits.

Comparison of the BIC values determined how a representative parameter estimation for $\operatorname{Tr}, Z$ and $\sigma$ for each micro-organism could be obtained. $t$-Statistics was carried out to calculate the mean and standard deviation of the fit results of the individual cultivations. Weighted means and weighted standard deviations were calculated to compensate for the number of data points of each individual cultivation.

The $95 \%$ Confidence Interval (95\% CI) of the Tc function with representative parameters was determined by Monte Carlo simulations ( $n=5000$ simulations, Excel), where the 5\% and 95\% quantiles of the observed data define the parameter interval around the Maximum
Likelihood. This method accounts for possible unsymmetrical confidence intervals occurring from non-linear regression, in contrast to linear approximation methods used in most software packages.

\section{Results and discussion}

\subsection{Validation of the model on E. coli data-set}

Thermal inactivation kinetics with variables $T$ and $t$ was carried out for individual overnight cultures of $E$. coli prepared at 8 different days, but cultivated from the same frozen stock culture. The data set of the

Table 2

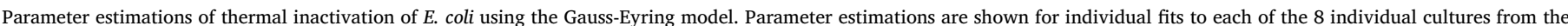

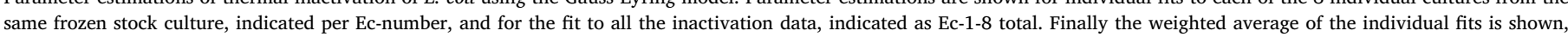
indicated as Ec-average. Values between brackets show the $95 \%$ confidence interval estimated for the parameters.

\begin{tabular}{|c|c|c|c|c|c|c|c|c|c|}
\hline Cell cultivation & $n$ & $t[\mathrm{~s}]$ & $T\left[{ }^{\circ} \mathrm{C}\right]$ & $\sigma\left({ }^{\circ} \mathrm{C}\right)$ & $\operatorname{Tr}(\mathrm{t}=1)\left({ }^{\circ} \mathrm{C}\right)$ & $Z\left({ }^{\circ} \mathrm{C}\right)$ & $\mathrm{R}^{2}$ & $\mathrm{SSr}$ & BIC \\
\hline Ec $1-8$, per cultivation & 304 & & & & & & 0.92 & 42.3 & -462.2 \\
\hline Ec-1, isotime & 40 & 4,14 & {$[56: 66][55: 63]$} & $1.10[1.01-1.20]$ & $64.5[64.1-65.0]$ & $5.3[4.9-5.7]$ & 0.98 & 2.5 & \\
\hline Ec-2, isotime & 64 & 34,64 & {$[53: 61][52: 60]$} & 1.16 [1.04-1.32] & $66.4[65.7-67.1]$ & $6.5[6.1-6.8]$ & 0.93 & 17.4 & \\
\hline Ec-3, isotime & 66 & $14,34,124,184$ & $\begin{array}{l}{[54: 61][57: 60]} \\
{[48: 58][48: 57]}\end{array}$ & 1.83 [1.67-2.02] & $68.2[67.0-69.4]$ & $8.4[7.7-9.1]$ & 0.94 & 8.2 & \\
\hline Ec-4, isothermal & 14 & {$[34: 244][34: 64]$} & 55,58 & $1.11[0.94-1.35]$ & $67.4[66.4-68.4]$ & $7.0[6.4-7.7]$ & 0.99 & 0.4 & \\
\hline Ec-5, isothermal & 18 & {$[34: 364][34: 124]$} & 54,56 & $1.20[0.96-1.60]$ & $63.7[62.1-65.3]$ & $5.9[4.8-6.9]$ & 0.96 & 1.9 & \\
\hline Ec-6, isothermal & 24 & {$[34: 294][34: 144]$} & 52,56 & $1.14[0.98-1.36]$ & $70.8[69.0-72.5]$ & $8.4[7.6-9.1]$ & 0.96 & 0.8 & \\
\hline Ec-7, isothermal & 18 & {$[14: 94][14: 44]$} & 58,60 & $0.81[0.68-1.01]$ & 65.7 [64.7-66.7] & $5.7[5.1-6.4]$ & 0.96 & 2.6 & \\
\hline Ec-8, isothermal & 60 & {$[64: 1504][64: 454][34: 244]$} & $52,54,56$ & 1.83 [1.58-2.18] & $65.4[65.3-65.5]$ & $6.6[6.0-7.2]$ & 0.91 & 8.5 & \\
\hline Ec $1-8$, total & 304 & & & $1.32[1.23-1.42]$ & $64.5[64.1-64.9]$ & $5.8[5.7-6.0]$ & 0.86 & 122.7 & -258.7 \\
\hline Ec-average of cultivations & 8 & & & $1.41[0.65-2.17]$ & $66.5[62.9-70.1]$ & $6.9[4.7-9.0]$ & - & & \\
\hline
\end{tabular}

$n$ : number of $t-T$ data points within a cell culture.

$\sigma, \operatorname{Tr}$ and $Z$ : parameter estimations according to Gauss-Eyring model (Eqs. (3a) and (3b)).

$\mathrm{R}^{2}$ : determination coefficient.

SSr: residual sum of squares.

BIC: Bayesian Information Criterion. 

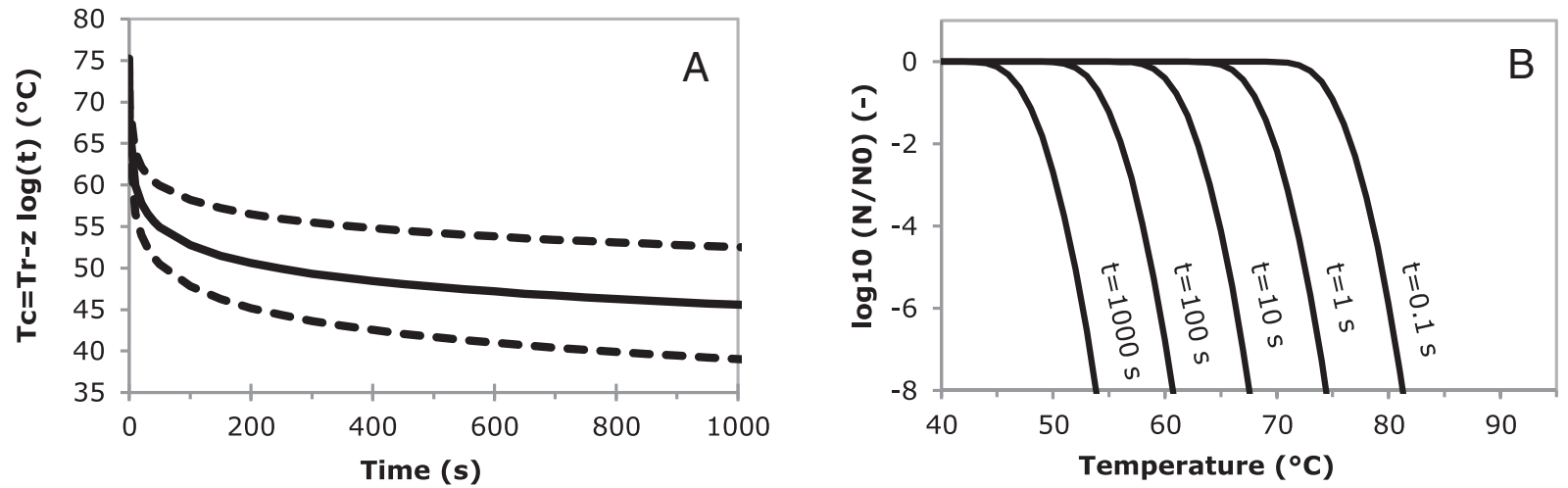

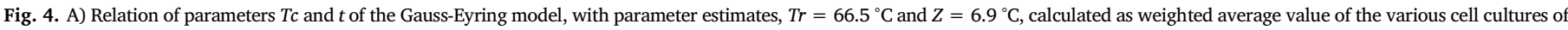

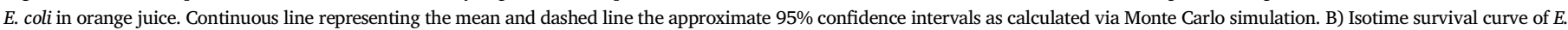
coli in orange juice calculated for different holding times using the Gauss-Eyring model and weighted parameter estimates of $8 \mathrm{cultures,} \sigma=1.41{ }^{\circ} \mathrm{C}$, $\mathrm{Tr}=66.5^{\circ} \mathrm{C}$ and $Z=6.9^{\circ} \mathrm{C}$.
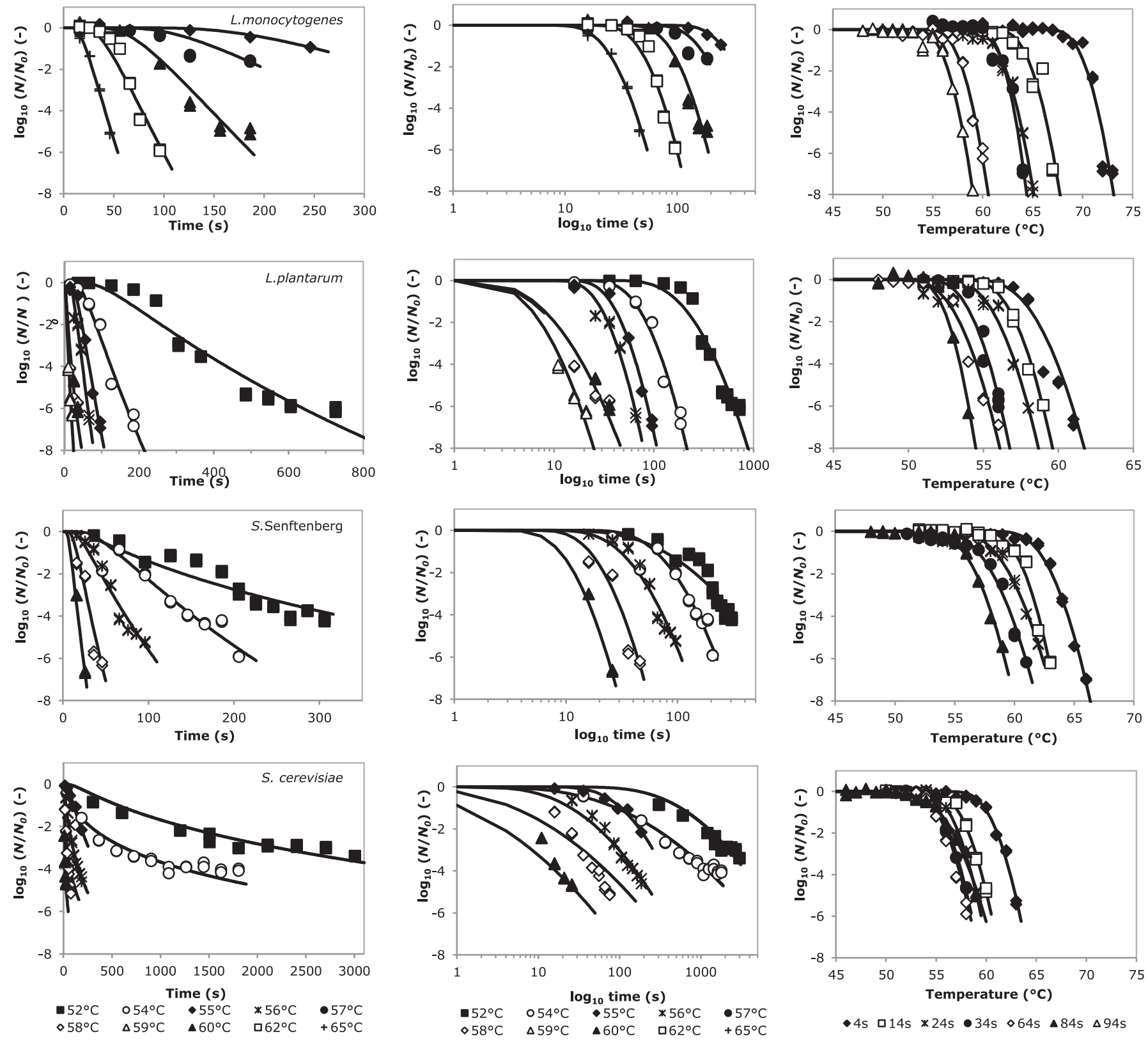

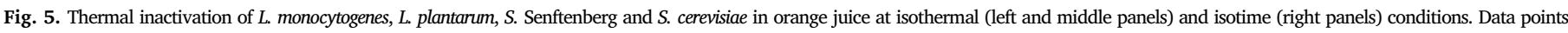

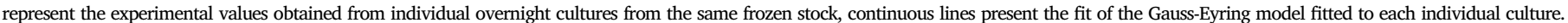


Table 3

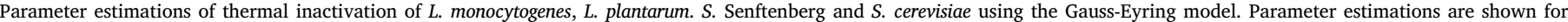

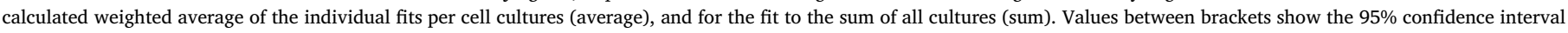
estimated for the parameters. Results of individual fits per culture are shown in the appendix.

\begin{tabular}{|c|c|c|c|c|c|c|c|}
\hline Strain & $n$ & $\sigma\left({ }^{\circ} \mathrm{C}\right)$ & $\operatorname{Tr}(t=1)\left({ }^{\circ} \mathrm{C}\right)$ & $Z\left({ }^{\circ} \mathrm{C}\right)$ & $\mathrm{R}^{2}$ & $\mathrm{SSr}$ & BIC \\
\hline \multicolumn{8}{|l|}{ L. monocytogenes } \\
\hline Fit to 10 cultures & 273 & & & & 0.96 & 47.2 & -344.2 \\
\hline Average of cultures & 4 & $0.89[0.58-1.21]$ & 74.7 [72.1-77.2] & $9.0[6.2-11.7]$ & & & \\
\hline Fit to sum of cultures & 273 & $1.38[1.23-1.57]$ & $70.8[69.9-71.6]$ & $7.6[7.3-8.0]$ & 0.65 & 404.2 & 123.4 \\
\hline \multicolumn{8}{|l|}{ L. plantarum } \\
\hline Fit to 12 cultures & 266 & & & & 0.95 & 71.3 & -160.4 \\
\hline Average of cultures & 10 & $0.79[0.30-1.28]$ & $61.8[58.2-65.3]$ & $5.3[2.9-7.8]$ & & & \\
\hline Fit to sum of cultures & 266 & 1.29 [1.16-1.45] & 58.8 [58.1-59.6] & $4.5[4.2-4.8]$ & 0.65 & 527.4 & 198.2 \\
\hline \multicolumn{8}{|l|}{ S. Senftenberg } \\
\hline Fit to 11 cultures & 309 & & & & 0.95 & 61.7 & -320.0 \\
\hline Average of cultures & 9 & $1.23[0.55-1.91]$ & $64.5[60.4-68.7]$ & $6.4[3.9-8.9]$ & & & \\
\hline Fit to sum of cultures & 309 & 1.49 [1.37-1.64] & $64.2[63.5-64.9]$ & $6.9[6.6-7.2]$ & 0.74 & 312.4 & 20.6 \\
\hline \multicolumn{8}{|l|}{ S. cerevisiae } \\
\hline Fit to 11 cultures & 318 & & & & 0.96 & 20.2 & -697.3 \\
\hline Average of cultures & 9 & $1.00[0.55-1.45]$ & $61.0[57.5-64.6]$ & $4.2[2.1-6.3]$ & & & \\
\hline Fit to sum of cultures & 318 & 1.36 [1.27-1.47] & 59.1 [58.8-59.5] & $3.3[3.2-3.4]$ & 0.85 & 130.8 & -265.2 \\
\hline
\end{tabular}

$n$ : number of $t-T$ data points within a cell culture.

$\sigma, \operatorname{Tr}$ and $Z$ : parameter estimations according to Gauss-Eyring model (Eqs. (3a) and (3b)).

$\mathrm{R}^{2}$ : determination coefficient.

SSr: residual sum of squares.

BIC: Bayesian Information Criterion.

different cultures was based on either isothermal or isotime inactivation kinetics. A representation of the measured inactivation data with model fit of the individual data is shown in Fig. 3 (upper panel), and fit results of all cultivations are shown in Table 2. It can be observed that the Gauss-Eyring model fits well to both isothermal and isotime inactivation data, as residuals are randomly distributed, and a low value of $\mathrm{SSr}$ was found. This resulted in a high value for $\mathrm{R}^{2}$ (determination coefficient, calculated as the 1-SSr / SStotal) and small 95\% confidence interval for the parameter estimates. Comparison of the parameter estimates for the different cultures showed some (small) deviations, suggesting that variability is introduced by cultivation of the different individual precultures, as the individual fits were all good.

Next, the Gauss-Eyring model was fitted to the combined inactivation data of the 8 individual cultures at once. Parameter estimates are shown in Table 2 indicated as 'total', together with the $95 \%$ confidence interval for the fit parameters. The small confidence intervals are the result of the relative large number of data points used $(n=304)$. However, it is clear that the sum of the residuals is large in this fit, describing the variance of the individual measured data points to the predicted model. This variation might be ascribed to the variability found between different individually grown cultures. This could have resulted from heterogeneity in the stock culture, introducing different single colonies to start the different cell cultivations, but it could also result from spontaneous mutation during cultivation (Nahku et al., 2011).

Comparison of the two models, describing the inactivation for individual cultures or describing the inactivation as single fit to the sum of the cultures at once, was done using the BIC value. The model describing the inactivation per culture $(p=24, n=304$, BIC $=-462.2)$ is preferred over the model describing the sum of the cultures $(p=3$, $n=304$, BIC $=-258.7$ ), as the BIC value is significantly lower.

As the objective of this paper was to predict inactivation for an arbitrary chosen short (holding) time, one parameter estimate for $\operatorname{Tr}, Z$ and $\sigma$ is needed to calculate the level of inactivation at chosen time $t$. Since the model describing the inactivation per culture was preferred over the model describing the sum of the cultures, the parameter estimates $\operatorname{Tr}, Z$ and $\sigma$ should be based on the results for the individual cultures. Because the estimation of the individual parameters $\operatorname{Tr}, Z$ and $\sigma$ for the different cultures is rather precise (small $95 \%$ confidence interval), the average value for $\operatorname{Tr}, Z$ and $\sigma$ can be obtained by calculating the average of the estimates of the 8 individual cultures. As the parameter estimates of the cultures are based on a different number of data points ( $n$ ), a weight for each culture was calculated, with $n / n_{\text {total }}$.

A weighted average and weighted variance were calculated for $\operatorname{Tr}, Z$ and $\sigma$, and results of the mean and $95 \%$ confidence interval are shown in Table 2, with average for $\operatorname{Tr}=66.5^{\circ} \mathrm{C}, Z=6.9^{\circ} \mathrm{C}$ and $\sigma=1.41{ }^{\circ} \mathrm{C}$. A model fit of these weighted parameter estimates to the measured inactivation is shown in Fig. 3 (lower panel). In general, the single model with weighted parameter estimates (lower panel) fitted well to the observed data, including the data with shortest holding time. The deviations between the model and observed data can be attributed to the variability between the individual cultures, which is also incorporated in the $95 \%$ confidence interval of the parameter estimates. Predictions based on these parameter estimates should therefore include this variability as well, for instance by indicating the $95 \% \mathrm{CI}$.

A prediction by the function of $T c(t)$ based on the calculated average values of $\operatorname{Tr}$ and $Z$ is shown in Fig. 4A. It can be seen that a short (holding) time corresponds to a high value of $T c(t)$, and that a longer (holding) time corresponds to a lower $T c(t)$-value, which reduces slowly to a temperature around $45^{\circ} \mathrm{C}$. Interestingly, this relative low temperature - long time relation is typically used as holding time for sous-vide cooking, excluding the extra time needed to heat up the product to this temperature, product specific characteristics and safety margins (Baldwin, 2012). The 95\% confidence interval of the $T c(t)$ function was determined using Monte Carlo simulations, and bands are shown in Fig. 4A. It can be seen that the $95 \%$ confidence interval is relatively large and increasing over time. The width of this interval is determined by the variation in the parameters $\operatorname{Tr}$ and $Z$, which is relatively large in our example due to variability between the individual cultures. The increase of this interval over time could be explained by the function itself, where $Z$ is multiplied by $\log _{10}(t)$. The uncertainty in the parameter $Z$ will therefore be propagated with a factor $\log _{10}(t)$, leading to wider confidence bands at longer times.

In Fig. 4B, the predicted inactivation as a function of temperature is shown for different (holding) times. The inactivation is determined with the calculated parameter estimates and the Gauss-Eyring model. It can be seen that the curvature of the inactivation is the same, and that the inactivation curve only shifts with the temperature-axis by changing the holding time, also for short holding times.

\subsection{Validation of the model on other species}

The approach described in the previous section for $E$. coli in orange 

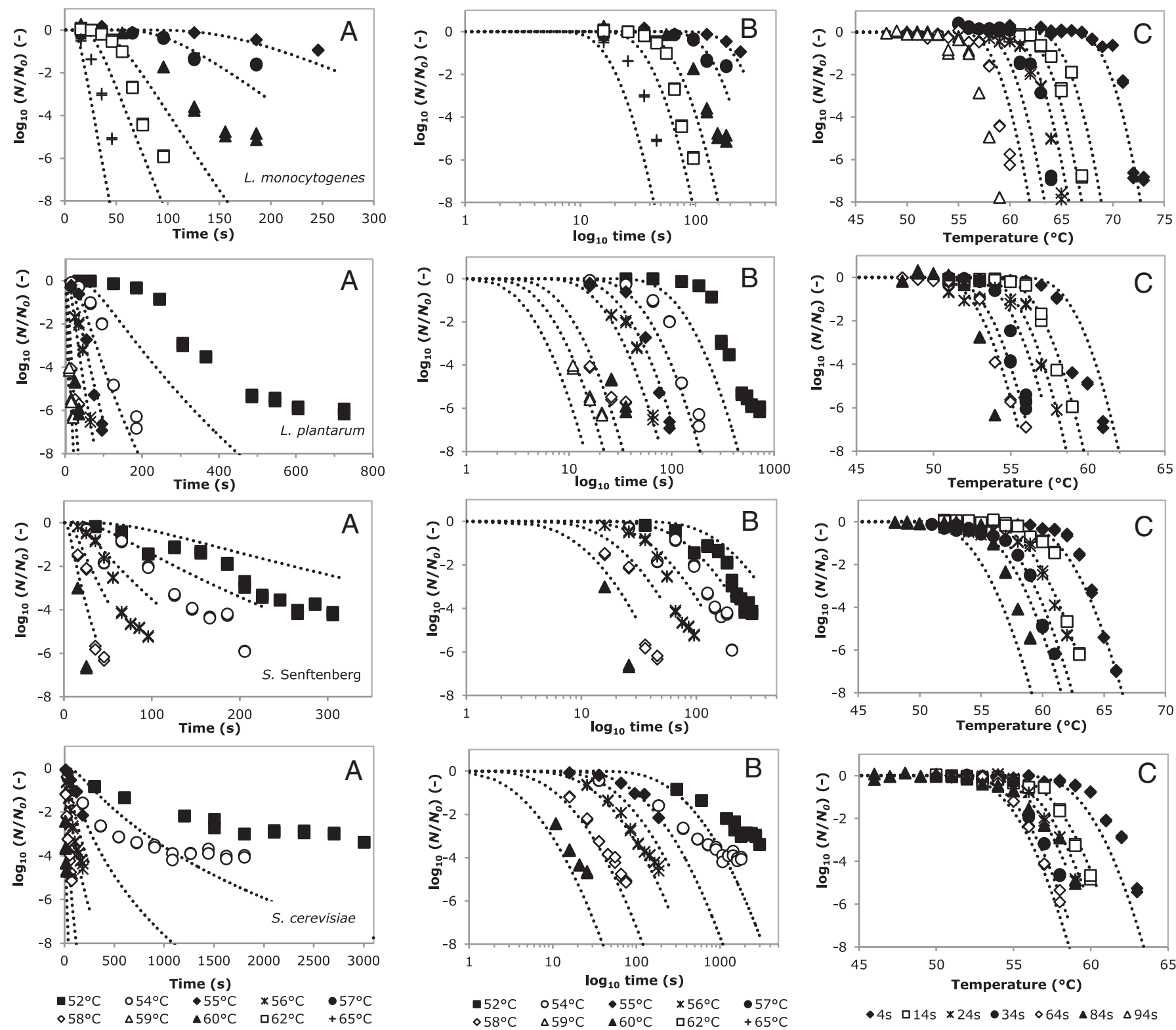

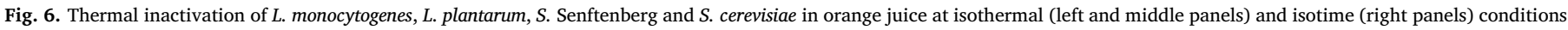

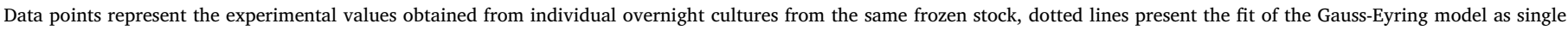
model with parameter estimations based on the average of cultivations.

juice, was tested for $L$. monocytogenes, L. plantarum, S. Senftenberg, and $S$. cerevisiae strains in orange juice as well. Individual overnight cultures were made at different days, and isothermal and isotime survival kinetics were determined. For some of the cultivations, in particular for $L$. monocytogenes, only one isotime condition for a cultivation was measured. This resulted in an estimated parameter $T c$ for the specific $t$, without estimations for $\operatorname{Tr}$ at $t=1$ and $Z$.

Results for the individual fits to the measured data for each individual culture and strain are shown in Fig. 5. Parameter estimates and fit results for the individual cultures are shown in the Appendix Tables A1-A4, and a summary of the results is shown in Table 3. Generally, a proper fit of the model to the data of each individual culture was found, with a random distribution of the residuals and a low value for the SSr. This resulted in a small confidence interval for the estimated parameters.

Heterogeneity within some individual cultures was observed, i.e. $L$. plantarum at $52{ }^{\circ} \mathrm{C}$, and could be described by the presence of two subpopulations, as discussed and illustrated in Mastwijk et al. (2017).
As the fit to one population (performed in this study using Eqs. (3a) and (3b) was not bad and residuals were distributed randomly, further quantification and characterisation of the inactivation data to two subpopulations, as demonstrated in Mastwijk et al. (2017), was not included in this study.

Variability between the individual cultures was observed as well, leading to differences in the parameter estimates. This variability was also observed when the Gauss-Eyring model was fitted to all inactivation data of a strain. The total SSr increased dramatically, and consequently also the BIC value (Table 3). Therefore, the weighted average mean and standard deviation were calculated from the parameter estimates of the individual cultures. Note that this average is based on only 4 values for L. monocytogenes, as datasets for this strain contained a relatively high number of single (holding) time tested in the individual culture, lacking parameter estimates of $\operatorname{Tr}$ and $Z$. A fit of the Gauss-Eyring model as single model with parameter estimations based on the weighted average of cultivations is shown to the observed data (Fig. 6). Although this single model did show 

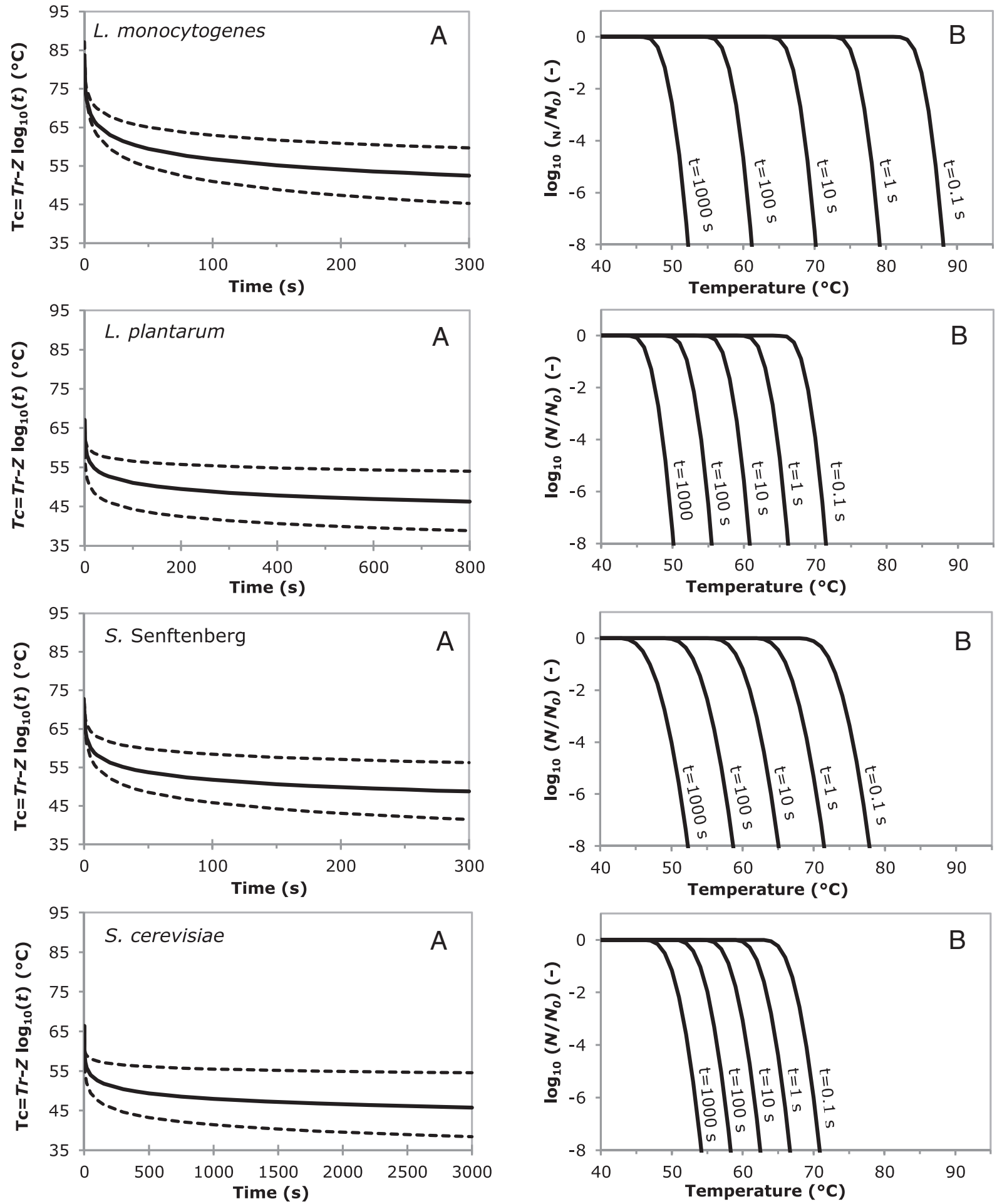

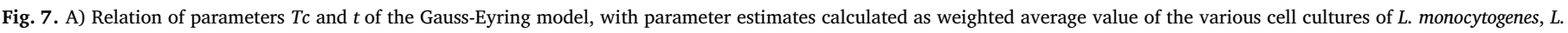

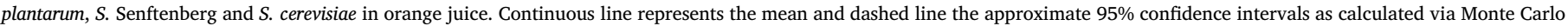

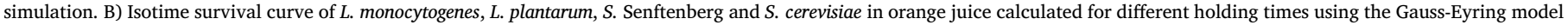
and weighted parameter estimates of the cultures. 
some deviation from the observed data, these deviations were relatively small at the shortest holding times measured, and therefore this single model could be used for predictions at even shorter holding times.

A plot of the $T c(t)$ function based on the calculated weighted parameter estimations and prediction of the isotime inactivation curves for various holding times is shown in Fig. 7. The differences between the parameter estimates for the different species show a clear effect on the $T c(t)$ function (Fig. 6A) and inactivation curves (Fig. 7B).

Comparison of the parameter estimates for the different species, including those for $E$. coli, showed that the estimated value of parameter $\sigma$ is comparable for all species, varying between 0.79 and 1.41. This means that at the same critical temperature-time combination Tc $(t)$, all strains have the same degree of inactivation, under the same experimental circumstances tested. Nevertheless, the parameter estimations of $\operatorname{Tr}$ and $Z$ are not the same for all species, and resistance tested in this study follows the order L. monocytogenes $>$ E. coli $>S$. Senftenberg $>L$. plantarum $>S$. cerevisiae. This is also shown in Fig. 7B, where inactivation curves of $L$. monocytogenes start at higher temperatures compared to those of other micro-organisms, due to higher $T r$-values. Furthermore, larger temperature distances between the different inactivation curves with variable holding times are shown for $L$. monocytogenes, showing the effect of a larger $Z$-value.

The mentioned $Z$-value in the Gauss-Eyring model is comparable to the $Z$ value reported for linear inactivation kinetics in literature, as they both represent the temperature required to change the $D_{T}$ or $\operatorname{Tr}$ value by a factor of 10. The value for $Z$ is dependent on the species, strains, cultivation protocol and medium characteristics (Van Asselt and Zwietering, 2006; Mazzotta, 2001; Smelt and Brul, 2014). Direct comparison of the Z-values obtained in this study to literature is therefore not possible. However, the $Z$-values in our study are comparable to results of Mazzotta (2001), who reported average Zvalues of $6.1 \pm 0.3{ }^{\circ} \mathrm{C}$ in fruit juices for mixtures of $L$. monocytogenes, $5.8 \pm 0.3^{\circ} \mathrm{C}$ for Salmonella mixtures and $5.3 \pm 0.4{ }^{\circ} \mathrm{C}$ E. coli $\mathrm{O} 157: \mathrm{H7}$ mixtures. Strains known for higher thermal resistance as for example $S$. Senftenberg showed higher resistance than other Salmonella strains ( $\mathrm{Ng}$ et al., 1969). Doyle and Mazzotta (2000) reported $Z$-values of $S$. Senftenberg in buffer between 6.8 and $7.7^{\circ} \mathrm{C}$, which is similar to the $Z$-value in orange juice calculated in this study.

\section{Conclusion}

In this study the Gauss-Eyring model was exploited to describe nonlinear thermal inactivation for vegetative micro-organisms, and as a model suitable to predict inactivation at short (holding) times. Due to the short come up time and cooling time in the set-up of the experimental part, only holding time was incorporated as time in the Gauss-Eyring model.

Parameter estimates $\sigma, \operatorname{Tr}$ and $Z$-value were determined from experimental isothermal and isotime data and fitted well to the individual cultures. Variability between the different cultures of the five tested microorganisms was observed. Therefore, an average of the individual cultures was calculated, and used to predict inactivation as a function of temperature for chosen (short) holding times. The Gauss-Eyring model showed to be a suitable model to predict inactivation at a single holding time with varying temperatures. This predicted inactivation curve will be used in a forthcoming publication to compare thermal inactivation to an alternative nonthermal inactivation process with short holding time.

\section{Acknowledgments}

Sincere thanks go to Eva Gil Rodríguez, Louise Nederhoff and Luciënne Berendsen for their assistance in the practical work, to Eric Boer for his assistance in the statistics, and to Ariette Matser for helpful discussions.

The research is part of the PPS Mild Preservation, which was co-financed by the Dutch Ministry of Economic Affairs, project number TKI-AF-12148.

\section{Appendix}

Table A1

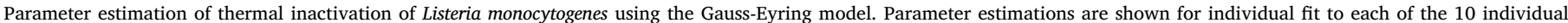

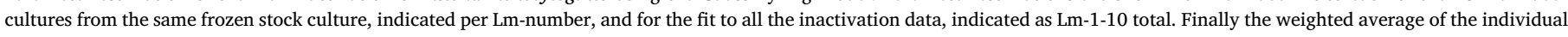

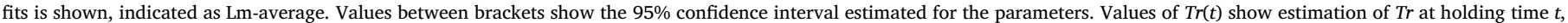
estimated for series with one fixed time.

\begin{tabular}{|c|c|c|c|c|c|c|c|c|c|c|}
\hline Cell cultivation & $n$ & $t(\mathrm{~s})$ & $T\left({ }^{\circ} \mathrm{C}\right)$ & $\sigma\left({ }^{\circ} \mathrm{C}\right)$ & $\operatorname{Tr}(t)\left({ }^{\circ} \mathrm{C}\right)$ & $\begin{array}{l}\operatorname{Tr}(t=1) \\
\left({ }^{\circ} \mathrm{C}\right)\end{array}$ & $Z\left({ }^{\circ} \mathrm{C}\right)$ & $\mathrm{R}^{2}$ & $\mathrm{SSr}$ & $\mathrm{BIC}$ \\
\hline Lm 1-10, per cultivation & 273 & & & & & & & 0.96 & 47.2 & -344.2 \\
\hline Lm-1, isotime & 28 & 4 & {$[60: 73]$} & $\begin{array}{l}0.81 \\
{[0.68-1.00]}\end{array}$ & $\begin{array}{l}68.5 \\
{[67.8-69.3]}\end{array}$ & & & 0.93 & 10.1 & \\
\hline Lm-2, isotime & 14 & 14 & {$[60: 69]$} & $\begin{array}{l}1.09 \\
{[1.05-1.13]}\end{array}$ & $\begin{array}{l}63.7 \\
{[63.5-63.9]}\end{array}$ & & & 1.00 & 0.1 & \\
\hline Lm-3, isotime & 20 & 34 & {$[55: 64]$} & $\begin{array}{l}0.69 \\
{[0.59-0.84]}\end{array}$ & $\begin{array}{l}60.5 \\
{[60.0-61.0]}\end{array}$ & & & 0.96 & 3.7 & \\
\hline Lm-4, isotime & 32 & 14,24 & $\begin{array}{l}{[60: 67]} \\
{[58: 65]}\end{array}$ & $\begin{array}{l}0.84 \\
{[0.73-0.99]}\end{array}$ & & $\begin{array}{l}75.9 \\
{[74.1-77.6]}\end{array}$ & $\begin{array}{l}11.2 \\
{[9.8-12.6]}\end{array}$ & 0.94 & 10.1 & \\
\hline Lm-5, isotime & 20 & 24 & {$[55: 64]$} & $\begin{array}{l}0.66 \\
{[0.55-0.81]}\end{array}$ & $\begin{array}{l}60.7 \\
{[60.2-0.53]}\end{array}$ & & & 0.96 & 3.8 & \\
\hline Lm-6, isotime & 21 & 34 & {$[50: 60]$} & $\begin{array}{l}0.77 \\
{[0.67-0.89]}\end{array}$ & $\begin{array}{l}56.3 \\
{[55.8-56.7]}\end{array}$ & & & 0.98 & 2.1 & \\
\hline Lm-7, isotime & 23 & 64 & [48:59] & $\begin{array}{l}0.76 \\
{[0.70-0.83]}\end{array}$ & $\begin{array}{l}54.8 \\
{[54.5-55.1]}\end{array}$ & & & 0.99 & 1.8 & \\
\hline Lm-8, isothermal & 54 & $\begin{array}{l}{[14: 244]} \\
{[14: 184]} \\
{[14: 94][14: 64]} \\
{[14: 44]}\end{array}$ & $55,57,60,62,65$ & $\begin{array}{l}1.06 \\
{[0.97-1.17]}\end{array}$ & & $\begin{array}{l}75.6 \\
{[74.6-76.5]}\end{array}$ & $\begin{array}{l}9.1 \\
{[8.7-9.6]}\end{array}$ & 0.95 & 3.8 & \\
\hline
\end{tabular}




\begin{tabular}{|c|c|c|c|c|c|c|c|c|c|}
\hline Lm-9, isothermal & 29 & $\begin{array}{l}{[14: 184]} \\
{[14: 94]}\end{array}$ & 60,62 & $\begin{array}{l}0.73 \\
{[0.61-0.92]}\end{array}$ & $\begin{array}{l}72.6 \\
{[71.3-74.0]}\end{array}$ & $\begin{array}{l}7.1 \\
{[6.3-7.9]}\end{array}$ & 0.95 & 6.1 & \\
\hline Lm-10, isothermal & 32 & $\begin{array}{l}{[34: 544]} \\
{[34: 304]}\end{array}$ & 55,57 & $\begin{array}{l}0.77 \\
{[0.65-0.95]}\end{array}$ & $\begin{array}{l}73.8 \\
{[71.7-75.8]}\end{array}$ & $\begin{array}{l}8.1 \\
{[7.2-8.9]}\end{array}$ & 0.95 & 4.9 & \\
\hline Lm 1-10, total & 273 & & & $\begin{array}{l}1.38 \\
{[1.23-1.57]}\end{array}$ & $\begin{array}{l}70.8 \\
{[69.9-71.6]}\end{array}$ & $\begin{array}{l}7.6 \\
{[7.3-8.0]}\end{array}$ & 0.65 & 404.2 & 123.4 \\
\hline Lm-average of cultivation & 4 & & & $\begin{array}{l}0.89 \\
{[0.58-1.21]}\end{array}$ & $\begin{array}{l}74.7 \\
{[72.1-77.2]}\end{array}$ & $\begin{array}{l}9.0 \\
{[6.2-11.7]}\end{array}$ & & & \\
\hline
\end{tabular}

$n$ : number of $t-T$ data points within a cell culture.

$\sigma, \operatorname{Tr}$ and $Z$ : parameter estimations according to Gauss-Eyring model (Eqs. (3a) and (3b)).

$\mathrm{R}^{2}$ : determination coefficient.

SSr: residual sum of squares.

BIC: Bayesian Information Criterion

Table A2

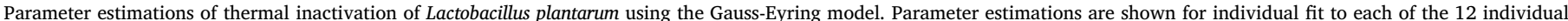

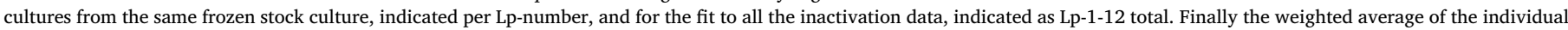

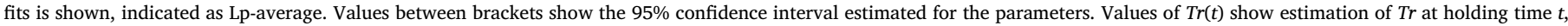
estimated for series with one fixed time.

\begin{tabular}{|c|c|c|c|c|c|c|c|c|c|c|}
\hline Cell cultivation & $n$ & $t(\mathrm{~s})$ & $T\left({ }^{\circ} \mathrm{C}\right)$ & $\sigma\left({ }^{\circ} \mathrm{C}\right)$ & $\operatorname{Tr}(t)\left({ }^{\circ} \mathrm{C}\right)$ & $\begin{array}{l}\operatorname{Tr}(t=1) \\
\left({ }^{\circ} \mathrm{C}\right)\end{array}$ & $Z\left({ }^{\circ} \mathrm{C}\right)$ & $\mathrm{R}^{2}$ & $\mathrm{SSr}$ & $\mathrm{BIC}$ \\
\hline $\begin{array}{l}\text { Lp } 1-12 \text {, per } \\
\text { cultivation }\end{array}$ & 266 & & & & & & & 0.95 & 71.3 & -160.4 \\
\hline Lp-1, isotime & 27 & 64,84 & $\begin{array}{l}{[49: 55]} \\
{[48: 54]}\end{array}$ & $\begin{array}{l}0.55 \\
{[0.50-0.61]}\end{array}$ & & $\begin{array}{l}64.2 \\
{[62.0-66.4]}\end{array}$ & $\begin{array}{l}6.7 \\
{[5.5-7.8]}\end{array}$ & 0.98 & 2.0 & \\
\hline Lp-2, isotime & 20 & 24,184 & $\begin{array}{l}{[51: 58]} \\
{[52: 53]}\end{array}$ & $\begin{array}{l}0.82 \\
{[0.66-1.07]}\end{array}$ & & $\begin{array}{l}62.5 \\
{[61.6-63.4]}\end{array}$ & $\begin{array}{l}6.1 \\
{[5.6-6.5]}\end{array}$ & 0.95 & 6.9 & \\
\hline Lp-3, isotime & 12 & 4 & {$[55: 61]$} & $\begin{array}{l}0.95 \\
{[0.78-1.24]}\end{array}$ & $\begin{array}{l}56.4 \\
{[55.4-57.3]}\end{array}$ & & & 0.94 & 5.4 & \\
\hline Lp-4, isotime & 17 & 14 & {$[51: 59]$} & $\begin{array}{l}0.75 \\
{[0.68-0.84]}\end{array}$ & $\begin{array}{l}55.4 \\
{[55.0-55.7]}\end{array}$ & & & 0.99 & 0.9 & \\
\hline Lp-5, isotime & 26 & 14,34 & $\begin{array}{l}{[51: 56]} \\
{[55: 59]}\end{array}$ & $\begin{array}{l}0.72 \\
{[0.63-0.83]}\end{array}$ & & $\begin{array}{l}62.5 \\
{[61.6-63.5]}\end{array}$ & $\begin{array}{l}6.4 \\
{[5.8-7.0]}\end{array}$ & 0.96 & 6.0 & \\
\hline Lp-6, isotime & 24 & 34,64 & $\begin{array}{l}{[54: 56]} \\
{[48: 56]}\end{array}$ & $\begin{array}{l}0.82 \\
{[0.70-0.98]}\end{array}$ & & $\begin{array}{l}58.5 \\
{[56.4-60.6]}\end{array}$ & $\begin{array}{l}3.9 \\
{[2.6-5.2]}\end{array}$ & 0.95 & 7.3 & \\
\hline Lp-7, isothermal & 18 & $\begin{array}{l}{[14: 124][14: 34]} \\
{[24: 34]}\end{array}$ & $55,58,60$ & $\begin{array}{l}1.45 \\
{[1.06-2.29]}\end{array}$ & & $\begin{array}{l}62.8 \\
{[59.1-66.5]}\end{array}$ & $\begin{array}{l}6.7 \\
{[4.8-8.5]}\end{array}$ & 0.79 & 18.0 & \\
\hline Lp-8, isothermal & 24 & {$[14: 184][14: 184]$} & 52,54 & $\begin{array}{l}0.48 \\
{[0.40-0.58]}\end{array}$ & & $\begin{array}{l}60.2 \\
{[58.7-61.6]}\end{array}$ & $\begin{array}{l}3.8 \\
{[3.0-4.6]}\end{array}$ & 0.98 & 2.5 & \\
\hline Lp-9, isothermal & 12 & {$[14: 64][14: 34]$} & 56,58 & $\begin{array}{l}1.23 \\
{[0.84-2.27]}\end{array}$ & & $\begin{array}{l}60.5 \\
{[57.8-63.2]}\end{array}$ & $\begin{array}{l}5.7 \\
{[3.4-8.0]}\end{array}$ & 0.86 & 6.2 & \\
\hline $\begin{array}{l}\text { Lp-10, } \\
\text { isothermal }\end{array}$ & 18 & {$[14: 94][24: 64]$} & 55,56 & $\begin{array}{l}0.80 \\
{[0.64-1.09]}\end{array}$ & & $\begin{array}{l}65.0 \\
{[62.9-67.1]}\end{array}$ & $\begin{array}{l}7.2 \\
{[5.6-8.7]}\end{array}$ & 0.98 & 2.4 & \\
\hline $\begin{array}{l}\text { Lp-11, } \\
\text { isothermal }\end{array}$ & 28 & {$[34: 724][9: 19]$} & 52,59 & $\begin{array}{l}0.73 \\
{[0.64-0.86]}\end{array}$ & & $\begin{array}{l}60.8 \\
{[60.1-61.4]}\end{array}$ & $\begin{array}{l}4.4 \\
{[4.2-4.5]}\end{array}$ & 0.94 & 9.4 & \\
\hline $\begin{array}{l}\text { Lp-12, } \\
\text { isothermal }\end{array}$ & 40 & $\begin{array}{l}{[24: 184][9: 19]} \\
{[9: 14]} \\
{[24: 74][14: 19]}\end{array}$ & $54,56,58,59,60$ & $\begin{array}{l}0.74 \\
{[0.68-0.80]}\end{array}$ & & $\begin{array}{l}61.3 \\
{[60.9-61.7]}\end{array}$ & $\begin{array}{l}4.4 \\
{[4.3-4.4]}\end{array}$ & 0.96 & 4.4 & \\
\hline Lp 1-12, total & 266 & & & $\begin{array}{l}1.29 \\
{[1.16-1.45]}\end{array}$ & & $\begin{array}{l}58.8 \\
{[58.1-59.6]}\end{array}$ & $\begin{array}{l}4.5 \\
{[4.2-4.8]}\end{array}$ & 0.65 & 527.4 & 198.2 \\
\hline $\begin{array}{l}\text { Lp-average of } \\
\text { cultivation }\end{array}$ & 10 & & & $\begin{array}{l}0.79 \\
{[0.30-1.28]}\end{array}$ & & $\begin{array}{l}61.8 \\
{[58.2-65.3]}\end{array}$ & $\begin{array}{l}5.3 \\
{[2.9-7.8]}\end{array}$ & & & \\
\hline
\end{tabular}

$n$ : number of $t-T$ data points within a cell culture.

$\sigma, \operatorname{Tr}$ and $Z$ : parameter estimations according to Gauss-Eyring model (Eqs. (3a) and (3b)).

$\mathrm{R}^{2}$ : determination coefficient.

SSr: residual sum of squares.

BIC: Bayesian Information Criterion. 
Table A3

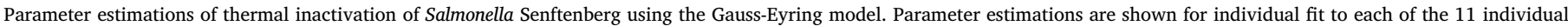

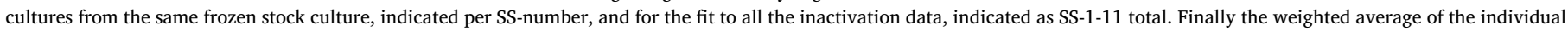

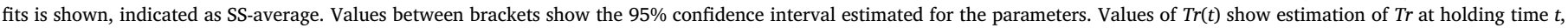
estimated for series with one fixed time.

\begin{tabular}{|c|c|c|c|c|c|c|c|c|c|c|}
\hline Cell cultivation & $n$ & $t(\mathrm{~s})$ & $T\left({ }^{\circ} \mathrm{C}\right)$ & $\sigma\left({ }^{\circ} \mathrm{C}\right)$ & $\operatorname{Tr}(t)\left({ }^{\circ} \mathrm{C}\right)$ & $\operatorname{Tr}(t=1)\left({ }^{\circ} \mathrm{C}\right)$ & $Z\left({ }^{\circ} \mathrm{C}\right)$ & $\mathrm{R}^{2}$ & $\mathrm{SSr}$ & $\mathrm{BIC}$ \\
\hline $\begin{array}{l}\text { SS } 1-11 \text {, per } \\
\text { cultivation }\end{array}$ & 309 & & & & & & & 0.95 & 61.7 & -320.0 \\
\hline SS-1, isotime & 22 & 84 & [48:59] & $\begin{array}{l}0.98 \\
{[0.91-1.06]}\end{array}$ & $\begin{array}{l}54.5 \\
{[54.2-54.8]}\end{array}$ & & & 0.99 & 0.7 & \\
\hline SS-2, isotime & 24 & 14 & {$[52: 63]$} & $\begin{array}{l}0.81 \\
{[0.71-0.93]}\end{array}$ & $\begin{array}{l}59.0 \\
{[58.6-59.5]}\end{array}$ & & & 0.97 & 2.6 & \\
\hline SS-3, isotime & 44 & 24,34 & $\begin{array}{l}{[52: 63]} \\
{[51: 61]}\end{array}$ & $\begin{array}{l}1.13 \\
{[1.05-1.24]}\end{array}$ & & $\begin{array}{l}67.7 \\
{[65.2-70.2]}\end{array}$ & $\begin{array}{l}7.3 \\
{[5.7-9.0]}\end{array}$ & 0.97 & 10.1 & \\
\hline SS-4, isotime & 28 & 4,14 & $\begin{array}{l}{[53: 67]} \\
{[58: 61]}\end{array}$ & $\begin{array}{l}1.53 \\
{[1.42-1.64]}\end{array}$ & & $\begin{array}{l}63.0 \\
{[62.2-63.8]}\end{array}$ & $\begin{array}{l}3.7 \\
{[3.0-4.4]}\end{array}$ & 0.99 & 0.2 & \\
\hline SS-5, isotime & 22 & 4,34 & $\begin{array}{l}{[58: 66]} \\
{[59: 60]}\end{array}$ & $\begin{array}{l}0.98 \\
{[0.90-1.07]}\end{array}$ & & $\begin{array}{l}64.8 \\
{[64.5-65.2]}\end{array}$ & $\begin{array}{l}6.6 \\
{[6.4-6.8]}\end{array}$ & 0.99 & 1.5 & \\
\hline SS-6, isothermal & 26 & {$[14: 184][14: 124]$} & 54,56 & $\begin{array}{l}0.83 \\
{[0.69-1.06]}\end{array}$ & & $\begin{array}{l}61.5 \\
{[59.9-63.1]}\end{array}$ & $\begin{array}{l}4.5 \\
{[3.5-5.5]}\end{array}$ & 0.91 & 7.7 & \\
\hline SS-7, isothermal & 24 & $\begin{array}{l}{[14: 184][14: 44]} \\
{[14: 24]}\end{array}$ & $52,58,60$ & $\begin{array}{l}0.92 \\
{[0.81-1.08]}\end{array}$ & & $\begin{array}{l}65.1 \\
{[64.1-66.0]}\end{array}$ & $\begin{array}{l}7.1 \\
{[6.7-7.6]}\end{array}$ & 0.96 & 4.8 & \\
\hline SS-8, isothermal & 22 & {$[14: 124][14: 94]$} & 54,56 & $\begin{array}{l}1.61 \\
{[1.16-2.67]}\end{array}$ & & $\begin{array}{l}67.8 \\
{[63.0-72.5]}\end{array}$ & $\begin{array}{l}8.1 \\
{[5.2-11.0]}\end{array}$ & 0.86 & 1.9 & \\
\hline SS-9, isothermal & 24 & $\begin{array}{l}{[14: 184][14: 44]} \\
{[14: 24]}\end{array}$ & $52,58,60$ & $\begin{array}{l}1.03 \\
{[0.93-1.15]}\end{array}$ & & $\begin{array}{l}64.7 \\
{[63.9-65.4]}\end{array}$ & $\begin{array}{l}6.6 \\
{[6.3-7.0]}\end{array}$ & 0.98 & 1.5 & \\
\hline SS-10, isothermal & 37 & {$[34: 304][14: 74]$} & 52,58 & $\begin{array}{l}1.87 \\
{[1.51-2.46]}\end{array}$ & & $\begin{array}{l}62.4 \\
{[59.8-64.9]}\end{array}$ & $\begin{array}{l}6.9 \\
{[5.9-7.9]}\end{array}$ & 0.75 & 22.4 & \\
\hline SS-11, isothermal & 36 & {$[24: 224][14: 94]$} & 54,56 & $\begin{array}{l}1.04 \\
{[0.84-1.38]}\end{array}$ & & $\begin{array}{l}63.7 \\
{[62.6-64.9]}\end{array}$ & $\begin{array}{l}6.2 \\
{[5.4-6.9]}\end{array}$ & 0.94 & 8.3 & \\
\hline SS 1-11, total & 309 & & & $\begin{array}{l}1.49 \\
{[1.37-1.64]}\end{array}$ & & $\begin{array}{l}64.2 \\
{[63.5-64.9]}\end{array}$ & $\begin{array}{l}6.9 \\
{[6.6-7.2]}\end{array}$ & 0.74 & 312.4 & 20.6 \\
\hline $\begin{array}{l}\text { SS-average of } \\
\text { cultivation }\end{array}$ & 9 & & & $\begin{array}{l}1.23 \\
{[0.55-1.91]}\end{array}$ & & $\begin{array}{l}64.5 \\
{[60.4-68.7]}\end{array}$ & $\begin{array}{l}6.4 \\
{[3.9-8.9]}\end{array}$ & & & \\
\hline
\end{tabular}

$n$ : number of $t-T$ data points within a cell culture.

$\sigma, \operatorname{Tr}$ and $Z$ : parameter estimations according to Gauss-Eyring model (Eqs. (3a) and (3b)).

$\mathrm{R}^{2}$ : determination coefficient.

SSr: residual sum of squares.

BIC: Bayesian Information Criterion. 
Table A4

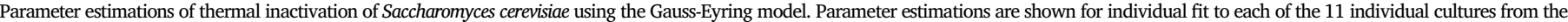

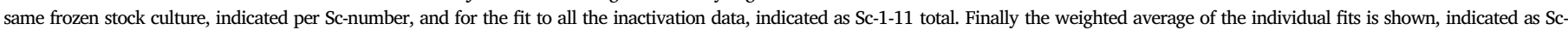

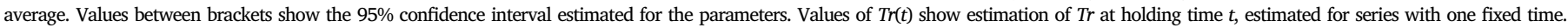

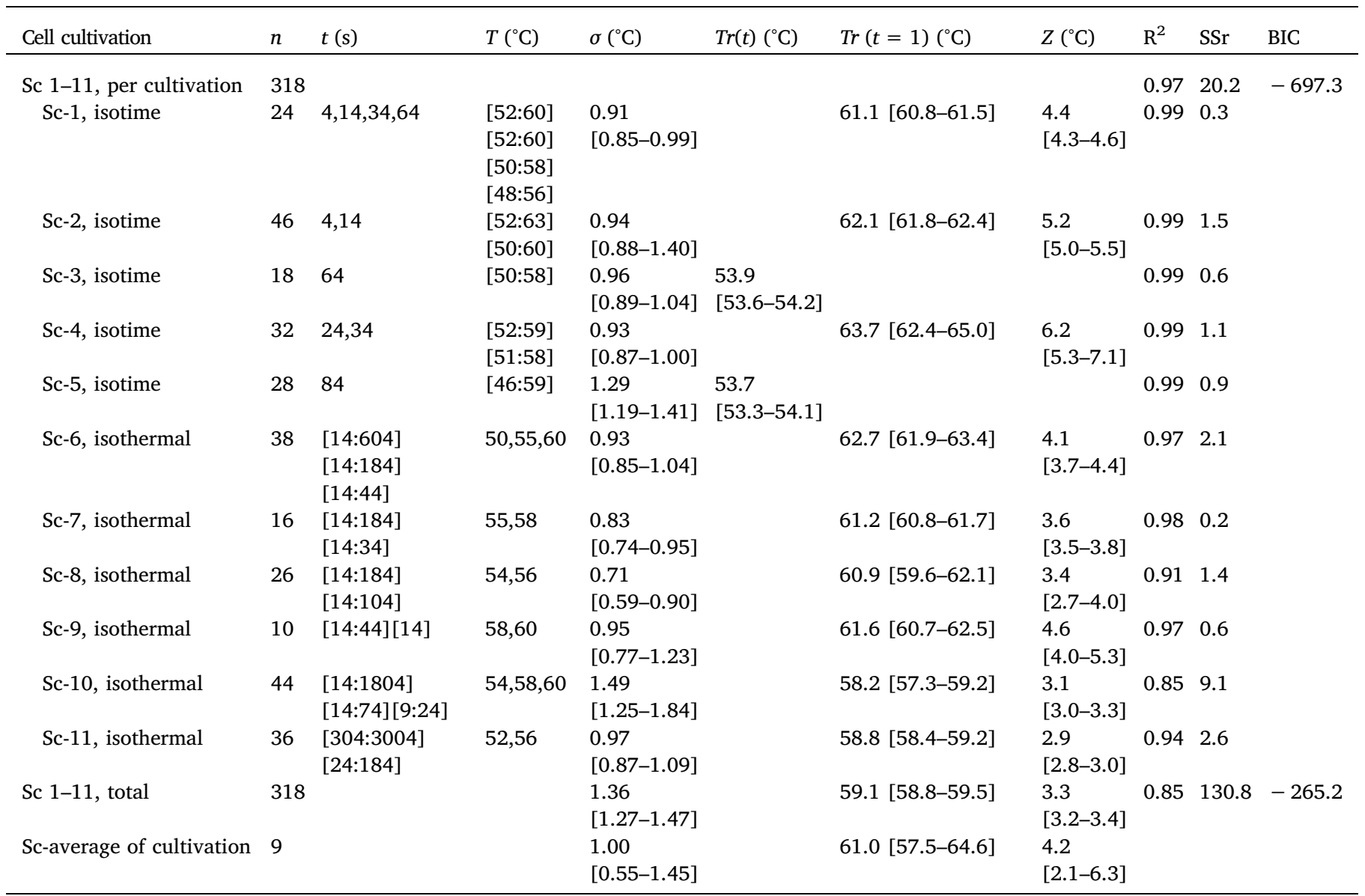

$n$ : number of $t-T$ data points within a cell culture.

$\sigma, \operatorname{Tr}$ and $Z$ : parameter estimations according to Gauss-Eyring model (Eqs. (3a) and (3b)).

$\mathrm{R}^{2}$ : determination coefficient.

SSr: residual sum of squares.

BIC: Bayesian Information Criterion.

\section{References}

Aragao, G.M.F., Corradini, M.G., Normand, M.D., Peleg, M., 2007. Evaluation of the Weibull and log normal distribution functions as survival models of Escherichia coli under isothermal and non isothermal conditions. Int. J. Food Microbiol. 119, 243-257.

Athena Visual Studio, 2016. Athena visual studio. Software for modeling, estimation and optimization, version 14.2. http://www.athenavisual.com.

Baldwin, D.E., 2012. Sous vide cooking: a review. International Journal of Gastronomy and Food Science 1, 15-30.

Cerf, O., 1977. Tailing of survival curves of bacterial spores. J. Appl. Microbiol. 42, 1-19.

R Core Team, 2016. R: A Language and Environment for Statistical Computing. R Foundation for Statistical Computing, Vienna, Austria.

Den Besten, H.M.W., Mataragas, M., Moezelaar, R., Abee, T., Zwietering, M.H., 2006. Quantification of the effects of salt stress and physiological state on thermotolerance of Bacillus cereus ATCC 10987 and ATCC 14579. Appl. Environ. Microbiol. 72, 5884-5894.

Doyle, M.E., Mazzotta, A.S., 2000. Review studies on the thermal resistance of Salmonella. J. Food Prot. 63, 779-795.

Geeraerd, A.H., Herremans, C.H., Van Impe, J.F., 2000. Structural model requirements to describe microbial inactivation during a mild heat treatment. Int. J. Food Microbiol. 59, 185-209.

Gil, M.M., Miller, F.A., Brandão, T.R.S., Silva, C.L.M., 2016. Combined effects of temperature, $\mathrm{pH}$ and water activity on predictive ability of microbial kinetic inactivation model. Procedia Food Science 7, 67-70.

Mastwijk, H.C., Timmermans, R.A.H., Van Boekel, M.A.J.S., 2017. The Gauss-Eyring model: a new thermodynamic model for biochemical and microbial inactivation kinetics. Food Chem. 237, 331-341.

Mazzotta, A.S., 2001. Thermal inactivation of stationary-phase and acid-adapted
Escherichia coli O157:H7, Salmonella, and Listeria monocytogenes in fruit juices. J. Food Prot. 64, 315-320.

McDonald, L.C., Hackney, C.R., Ray, B., 1983. Enhanced recovery of injured Escherichia coli by compounds that degrade hydrogen peroxide or block its formation. Appl. Environ. Microbiol. 45, 360-365.

Nahku, R., Peebo, K., Valgepea, K., Barrick, J.E., Adamberg, K., Vilu, R., 2011. Stock culture heterogeneity rather than new mutational variation complicates short-term cell physiology studies of Escherichia coli K-12 MG1655 in continuous culture. Microbiology 157, 2604-2610.

Ng, H., Bayne, H.G., Garibaldi, J.A., 1969. Heat resistance of Salmonella: the uniqueness of Salmonella Senftenberg 775. Appl. Microbiol. 17, 78-82.

Peleg, M., Cole, M.B., 1998. Reinterpretation of microbial survival curves. Crit. Rev. Food Sci. Nutr. 38, 353-380.

Peleg, M., Normand, M., 2004. Calculating microbial survival parameters and predicting survival curves from non-isothermal inactivation data. Crit. Rev. Food Sci. Nutr. 44, $409-418$.

Raso, J., Condón, S., Álvarez, I., 2014. Pulsed electric field. In: Batt, C.A. (Ed.), Encyclopedia of Food Microbiology, second ed. Elsevier ltd..

Reiff, F., 1965. Fundamentals of Statistical and Thermal Physics. 1965 McGraw-Hill.

Sharma, M., Adler, B.B., Harrison, M.D., Beuchat, L.R., 2005. Thermal tolerance of acidadapted and unadapted Salmonella, Escherichia coli O157:H7, and Listeria monocytogenes in cantaloupe juice and watermelon juice. Lett. Appl. Microbiol. 41, $448-453$.

Siemer, C., Toepfl, S., Heinz, V., 2014. Inactivation of Bacillus subtilis spores by pulsed electric fields (PEF) in combination with thermal energy - I. Influence of process- and product parameters. Food Control 39, 163-171.

Smelt, J.P.P.M., Brul, S., 2014. Thermal inactivation of microorganisms. Crit. Rev. Food Sci. Nutr. 54, 1371-1385.

Timmermans, R.A.H., Nierop Groot, M.N., Nederhoff, A.L., Van Boekel, M.A.J.S., Matser, A.M., Mastwijk, H.C., 2014. Pulsed electric field processing of different fruit juices: 
impact of $\mathrm{pH}$ and temperature on inactivation of spoilage and pathogenic microorganisms. Int. J. Food Microbiol. 173, 105-111.

Van Asselt, E.D., Zwietering, M.H., 2006. A systematic approach to determine global thermal inactivation parameters for various food pathogens. Int. J. Food Microbiol $107,73-82$

Van Boekel, M.A.J.S., 2002. On the use of the Weibull model to describe thermal inactivation of microbial vegetative cells. Int. J. Food Microbiol. 74, 139-159.
Van Boekel, M.A.J.S., 2008. Kinetic modeling of food quality: a critical review. Compr. Rev. Food Sci. Food Saf. 7, 144-158.

Whiting, R.C., 1993. Modeling bacterial survival in unfavourable environments. J. Ind. Microbiol. 12, 240-246.

Xiang, Y., Gubian, S., Suomela, B., Hoeng, J., 2013. Generalized simulated annealing for efficient global optimization: the GenSA package for R. The R Journal 5, 13-29. 